Research Paper

\title{
Bioactive characterization of Persea americana Mill. by-products: A rich source of inherent antioxidants
}

\author{
Bruno Melgar ${ }^{\mathrm{a}, \mathrm{b}}$, Maria Inês Dias ${ }^{\mathrm{a}}$, Ana Ciric ${ }^{\mathrm{c}}$, Marina Sokovic ${ }^{\mathrm{c}}$, Esperanza M. Garcia-Castello ${ }^{\mathrm{b}}$ \\ Antonio D. Rodriguez-Lopez ${ }^{\mathrm{d}}$, Lillian Barros ${ }^{\mathrm{a}}$, Isabel C.R.F. Ferreira ${ }^{\mathrm{a}, *}$ \\ ${ }^{a}$ Centro de Investigação de Montanha (CIMO), Instituto Politécnico de Bragança, Campus de Santa Apolónia, 5300-253, Bragança, Portugal \\ ${ }^{\mathrm{b}}$ Institute of Food Engineering for Development, Universitat Politècnica de València, Camino de Vera, s/n CP, 46022, Valencia, Spain \\ ' University of Belgrade, Department of Plant Physiology, Institute for Biological Research "Siniša Stanković", Bulevar Despota Stefana 142, 11000, Belgrade, Serbia \\ d Institute for Industrial, Radiophysical and Environmental Safety (ISIRYM), Universitat Politècnica de València, Camino de Vera, s/n CP, 46022, Valencia, Spain
}

\section{A R T I C L E I N F O}

\section{Keywords:}

Hass avocado

Polyphenols

Flavonoids

Antimicrobial activity

Antioxidant capacity

HPLC-DAD/ESI-MS

\begin{abstract}
A B S T R A C T
Avocado (Persea americana Mill.) is a worldwide consumed fruit, with great interest for cosmetic and pharmaceutical industries; however, $30 \%$ of avocado fruits are bio-wastes (peels and kernels), converting them into a potential source of bioactive compounds, such as phenolic compounds. Therefore, the hydroethanolic extracts of peels and kernels of Persea america Mill. var. Hass were analysed regarding their individual phenolic profile by HPLC-DAD/ESI-MS and correlated with their antioxidant, antimicrobial and cytotoxic activities. Avocado byproducts presented a very distinct phenolic profile, presenting higher concentration in peels $(227.9 \mathrm{mg} / \mathrm{g}$ of extract for total phenolic content), mainly in (epi)catechin derivatives $(175 \mathrm{mg} / \mathrm{g}$ of extract), followed by chlorogenic derivatives $(42.9 \mathrm{mg} / \mathrm{g}$ of extract). In this study hydrophilic and lipophilic antioxidant assays were performed together for the first time in P. americana by-products, and although kernels showed a great antioxidant potential $\left(\mathrm{EC}_{50}\right.$ values ranging from 18.1 to $276 \mu \mathrm{g} / \mathrm{mL}$ ), peels presented the highest potential $\left(\mathrm{EC}_{50}\right.$ ranging from 11.7 to $152 \mu \mathrm{g} / \mathrm{mL}$ ), mainly due to the presence of phenolic compounds, and an overall better performance in the antibacterial assays. Further studies needs to be conducted to better understand the correlation between the presence of phenolic compounds and bioactivities, however, the main objective is to implement these biocompounds in different products and industries, due to results obtained, $P$. americana peels could be a great alternative in the substitution of synthetic antioxidants.
\end{abstract}

\section{Introduction}

The world population is increasingly higher each year, which can reach 9.7 billion by the year 2050, leading to many concerns about food security issues, especially food inequity in undeveloped countries (UN DESA, 2015). The numbers are alarming, demonstrating great differences between countries, in this sense the Food and Agriculture Organisation report 795 millions of undernourishment people in the world (FAO et al., 2015) and the World Health Organisation published data where more than 1,9 billion adults are overweight (WHO, 2014).

Currently, some food crops are being exploited with purposes other than human feed, like the ones used to produce biofuels (Naik et al., 2010), broadening the food scarcity. Fortunately, food industries and academia have started to play special attention to food by-products in order of their revalorization, keeping a better control of waste management and finding alternatives to the usage of food crops in other applications (Ayala-Zavala et al., 2011; Librán et al., 2013; Sharma et al., 2017).

Avocado (Persea americana Mill.) is a dicotyledoneous plant from the Lauraceae family, native from south central Mexico, but with global consumption. It is manly consumed as a fresh fruit, although, food, cosmetic and pharmaceutical industries process its pulp in order to increase commercialisation and give a higher added value to avocado (FAO, 2004). There are several varieties within the $P$. americana species such as Bacon, Hass, Fuerte, Gwen, among many others, being Hass one of the most commercialise varieties. Hass avocados has around $14 \%$ and $16 \%$ of total fruit weight in its peels and kernel, respectively, accounting around $30 \%$ of its weight on by-products (Calderón-Oliver et al., 2016). The peels and pulps of many fruits, including avocado, contain a large amount of antioxidants that are responsible for the plant defence system, against different types of stresses, such as temperature and light (Ghasemzadeh and Ghasemzadeh, 2011; Manach et al., 2004). They are also known to have effects against some human degenerative diseases (Ghasemzadeh and Ghasemzadeh, 2011; Kaur Kala et al., 2016;

\footnotetext{
* Corresponding author.

E-mail address: iferreira@ipb.pt (I.C.R.F. Ferreira).
} 


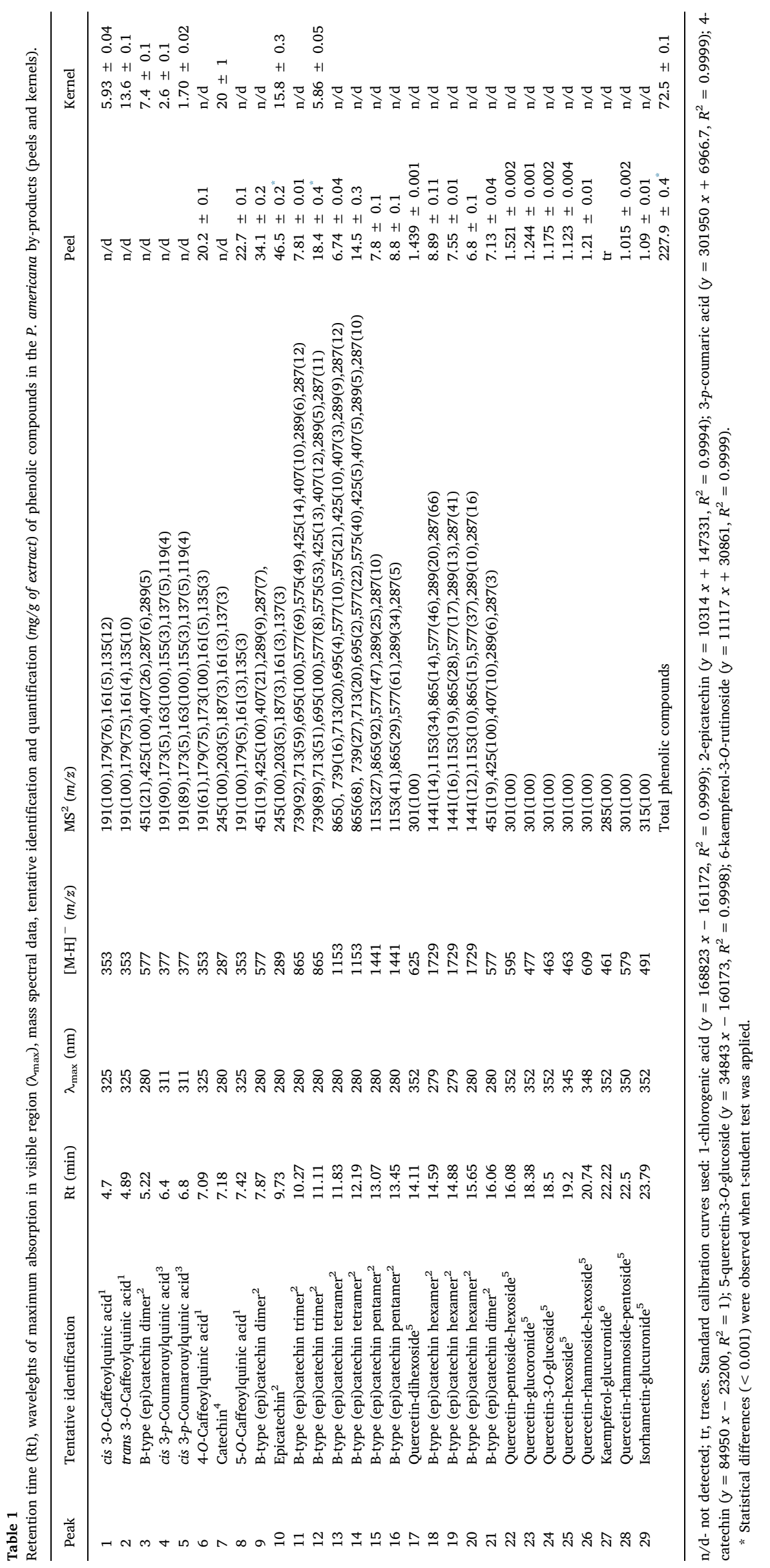


Šiler et al., 2014).

The recovery of bioactive compounds from different waste materials has been the main focus of many scientific studies, since the agro-industries valorise these by-products, generating a large amount of phytochemicals, that can be applied as functional food compounds or as food ingredients, (e.g. colorants, emulsifiers, thickeners, antioxidants, among others) (Azeredo, 2009; Dias et al., 2016; Gong and Bassi, 2016). Although numerous methodologies can be found in literature for bioactive compounds recovery like ultrafiltration, supercritical fluid extraction, ultrasound extraction, resin adsorption, encapsulation and spray drying among others (da Silva et al., 2016; Destro dos Santos et al., 2016; Kaderides and Goula, 2017; Li et al., 2012; Medina-Meza and Barbosa-Cánovas, 2015; Yamashita et al., 2017), five distinct recovery stages can principally be observed: macroscopic pre-treatment, macro and micromolecules separation, extraction, purification and nutraceuticals formation (Galanakis, 2012).

Due to the high volume of by-products generated from the avocado industries and the possibility of extracting functional biomolecules, the main focus of this study was to analyse the waste materials (peels and kernels) of Persea america Mill. var. Hass.

There are few avocado by-product studies in literature, and the existing articles report works with non-compatible solvents allowed by the food and pharmaceutical authorities (FDA, 2017), such as methanol or hexane (Kosińska et al., 2012; López-Cobo et al., 2016; RodríguezCarpena et al., 2011), hindering the use of their final extracts. For this reason, we decided to performed a complete research based on an efficient food grade solvent, working on the hydrophilic and lipophilic antioxidant profile, a deep characterization of the bioactive compounds through HPLC-DAD-ESI/MS was performed, a wider antimicrobial analysis employing more pathogenic strains than those already tested by other authors and adding up the cytotoxic potential assays, to finally compile all this information in order to acquire better understanding of their intrinsic compounds and functions, which would allow to find an adequate use of these by-products as an alternative natural ingredient.

\section{Material and methods}

\subsection{Samples preparation}

Ripen avocado (Persea americana Mill. var. Hass) were purchased from a local market in Bragança, Portugal and stored at $4{ }^{\circ} \mathrm{C}$ until further used. Within $24 \mathrm{~h}$, fruits were cut, peeled and separated in three fractions (peel, kernel and pulp). Pulp was discarded, peels were carefully cleaned and kernels were frozen. Afterwards, kernels and peels were lyophilized (LabConco, Frezone $-105{ }^{\circ} \mathrm{C}$, $4.5 \mathrm{~L}$ Cascade Benchtop Freeze Dry System, Kansas, MO, USA), grounded $(\sim 20$ mesh), and stored in a cool and dry place until further use.

\subsection{Extraction procedure}

Hydroethanolic extraction (ethanol: water, 80:20 v/v) was performed with $1 \mathrm{~g}$ of lyophilized peels and kernels, by magnetic stirring with $25 \mathrm{~mL}$ of aqueous ethanol $\left(25^{\circ} \mathrm{C}\right.$ at $\left.150 \mathrm{rpm}\right)$ for $1 \mathrm{~h}$ and subsequently filtered through the Whatman no. 4 paper. Supernatants were collected and tissues were re-extracted one more time with the same conditions. The obtained extracts were combined, and the ethanol was evaporated (rotary evaporator Büchi R-210, Flawil, Switzerland), the remaining aqueous phase was frozen and subsequently lyophilized.

The obtained dry extracts were re-dissolved in order to prepare stock solutions in (i) aqueous ethanol solution $80 \%$, for antioxidant activity evaluation (final concentration $40 \mathrm{mg} / \mathrm{mL}$ ) and for phenolic characterization (final concentration $5 \mathrm{mg} / \mathrm{mL}$ ); (ii) water (final concentration $8 \mathrm{mg} / \mathrm{mL}$ ) for cytotoxicity evaluation, and (iii) 5\% DMSO in distilled water (final concentration $10 \mathrm{mg} / \mathrm{mL}$ ) for antimicrobial properties. Stock solutions were further diluted to different concentration for the evaluation of distinct in vitro bioactivity assays.

\subsection{Phenolic compounds}

For phenolic profile characterization, LC-DAD-ESI/MS analyses were performed using a Dionex Ultimate 3000 UPLC instrument (ThermoScientific, San Jose, CA, USA), coupled to a diode-array detector (using several wavelengths, $280 \mathrm{~nm}, 330 \mathrm{~nm}$ and $370 \mathrm{~nm}$ ) and to a mass detector (Linear Ion Trap LTQ XL mass spectrometer, equipped with an ESI source, ThermoFinnigan, San Jose, CA, USA). The elution gradient, chromatographic and mass spectrometer conditions were performed according to the previously described by Bessada et al. (2016), Identification was performed by comparing their fragmentation pattern, retention times and UV-vis spectra with authentic standards, when available, or by comparing the obtained information with available data from literature. The quantification was performed using calibration curves of phenolic standards (chlorogenic acid, epicatechin, catechin and $p$-coumaric acid, quercetin-3-O-rutinoside, quercetin-3-Oglucoside, kaempferol 3-O-rutinoside and isorhamnetin-3-O-glucoside). When a standard was not available to quantify a phenolic compound, a similar compound of the same phenolic group was used (see Table 1). Phenolic compounds quantification results are present in $\mathrm{mg} / \mathrm{g}$ of extract.

\subsection{Bioactive properties evaluation}

\subsubsection{Antioxidant activity assays}

Stock solution from $P$. americana by-products were successively diluted and submitted to different in vitro assays (DPPH radical scavenging activity, reducing power, $\beta$-carotene bleaching inhibition and TBARS assay) to evaluate the antioxidant activity of the samples, following the previously described procedure by Vieira et al. (2016a). The results were expressed as $\mathrm{EC}_{50}$ values (sample concentration providing $50 \%$ of antioxidant activity or 0.5 of absorbance in the reducing power assay) for antioxidant activity. Trolox was used as positive control.

\subsubsection{Antimicrobial activity assays}

Antibacterial activity was assayed using the following, four Grampositive bacteria: Staphylococcus aureus (ATCC 6538), Bacillus cereus (clinical isolate), Micrococcus flavus (ATCC10240), and Listeria monocytogenes (NCTC7973) and four Gram-negative bacteria: Escherichia coli (ATCC 35210), Pseudomonas aeruginosa (ATCC 27853), Salmonella typhimurium (ATCC 13311), and Enterobacter cloacae (ATCC 35030). For the antifungal assays, seven microfungi were used: Aspergillus fumigatus (ATCC1022), Aspergillus ochraceus (ATCC12066), Aspergillus versicolor (ATCC11730), Aspergillus niger (ATCC6275), Penicillium funiculosum (ATCC 36839), Penicillium ochrochloron (ATCC9112), Penicillium verrucosum var. cyclopium (food isolate) and Trichoderma viride (IAM 5061).

The minimum inhibitory (MIC), minimum bactericidal concentrations (MBC) and minimum fungicidal concentrations (MFC) were determined by methodologies, described by (Gomes-Correa et al., 2015). The minimum inhibitory (MIC) and minimum bactericidal (MBC) concentrations were determined by the microdilution method. Each fresh overnight culture of bacteria was adjusted spectrophotometrically to a concentration of $1 \times 10^{5} \mathrm{CFU} / \mathrm{mL}$. The requested $\mathrm{CFU} / \mathrm{mL}$ corresponded to a bacterial suspension determined in a spectrophotometer at $625 \mathrm{~nm}$ (OD625). Dilutions of inocula were cultured on solid medium to verify the absence of contamination and check the validity of each inoculum. Different solvent dilutions of the ethanolic extract were added to the wells containing $100 \mu \mathrm{L}$ of Tryptic Soy Broth (TSB) and afterwards, $10 \mu \mathrm{L}$ of inoculum was added to all wells. The microplates were incubated for $24 \mathrm{~h}$ at $37^{\circ} \mathrm{C}$. The MIC of the samples was detected following the addition of $40 \mu \mathrm{L}$ of iodonitrotetrazolium chloride (INT) $(0.2 \mathrm{mg} / \mathrm{mL})$ and incubation at $37^{\circ} \mathrm{C}$ for $30 \mathrm{~min}$. The lowest concentration that produced a significant inhibition (around 50\%) of the growth of the bacteria in comparison with the positive control was identified as the MIC. The minimum inhibitory concentrations (MICs) obtained from the susceptibility testing of various bacteria to tested 
extracts were determined also by a colorimetric microbial viability assay based on the reduction of the INT color and compared with a positive control for each bacterial strain. MBC was determined by serial sub-cultivation of $10 \mu \mathrm{L}$ into microplates containing $100 \mu \mathrm{L}$ of TSB. The lowest concentration that showed no growth after this sub-culturing was read as the MBC.

The fungal spores were washed from the surface of agar plates with sterile $0.85 \%$ saline containing $0.1 \%$ Tween $80(\mathrm{v} / \mathrm{v})$. The spore suspension was adjusted with sterile saline to a concentration of approximately $1.0 \times 10^{5}$ in a final volume of $100 \mu \mathrm{L}$ per well. The inocula were stored at $4{ }^{\circ} \mathrm{C}$ for further use. Dilutions of each inoculum were cultured on solid MA to verify the absence of contamination and to check the validity of the inoculum. Minimum inhibitory concentration (MIC) determination was performed by a serial dilution technique using 96-well microtitre plates. The investigated extract was dissolved in a $5 \%$ solution of DMSO and added to broth malt medium with a fungal inoculum. The microplates were incubated for $72 \mathrm{~h}$ at $28^{\circ} \mathrm{C}$. The lowest concentrations without visible growth (as assessed using a binocular microscope) were defined as the MICs. The minimum fungicidal concentrations (MFCs) were determined by serial sub-cultivation of $2 \mu \mathrm{L}$ in microtitre plates containing $100 \mu \mathrm{L}$ of malt broth per well and further incubation for $72 \mathrm{~h}$ at $28{ }^{\circ} \mathrm{C}$. The lowest concentration with no visible growth was defined as the MFC, indicating $99.5 \%$ killing of the original inoculum.

Standard drugs, namely streptomycin and ampicillin, bifonazole and ketoconazole were used as positive controls, while 5\% DMSO was used as the negative control. Samples were tested in duplicate and experiments were repeated three times.

Bacterial and fungal organisms were obtained from the Mycological Laboratory, Department of Plant Physiology, Institute for Biological Research "Sinisa Stanković", University of Belgrade, Serbia and the results were expressed in $\mathrm{mg} / \mathrm{mL}$.

\subsection{Statistical analysis}

All the extractions and assays were performed in triplicate and results were expressed as mean values and standard deviation (SD). Results were analysed using a Students $t$-test, in order to determine the significant difference between the two samples, with $p=0.05$. The treatment was carried out using IBM SPSS Statistics for Windows, version 23.0. (IBM Corp., Armonk, New York, USA).

\section{Results and discussion}

\subsection{Phenolic profile of $P$. americana by-products}

Table 1 presents the peak characteristics (retention time, $\lambda_{\max }$ in the visible region, mass spectral data), tentative identifications and quantification of phenolic compounds in the hydroethanolic extracts from pulp and kernel of $P$. americana. Twenty-nine phenolic compounds were identified, fourteen flavan-3-ols ((epi)catechin derivatives), nine flavonoids (quercetin, kaempferol and isorhamnetin glycoside derivatives) and six phenolic acids (chlorogenic and coumaric acid derivatives). Peels and kernel present a very distinct profile being the only common compounds, peaks 10 and 12. The phenolic profile of avocado has been previously described by other authors in pulp (Hurtado-Fernández et al., 2013, 2014), peels (Kosińska et al., 2012) and seeds (Kosińska et al., 2012; Ramos-Jerz et al., 2013). However, many of the identified compounds were identified for the first time in avocado by-products. A representative chromatogram of peels and kernel are presented in Fig. 1.

The main family of phenolic compounds found in avocado peels and kernels were (epi)catechin derivatives. Peaks 7 and 10 were positively identified as (+)-catechin and (-)-epicatechin, respectively, by comparison with commercial standards taking into account also their retention time, mass and UV-vis characteristics. Peak 7 (catechin) was

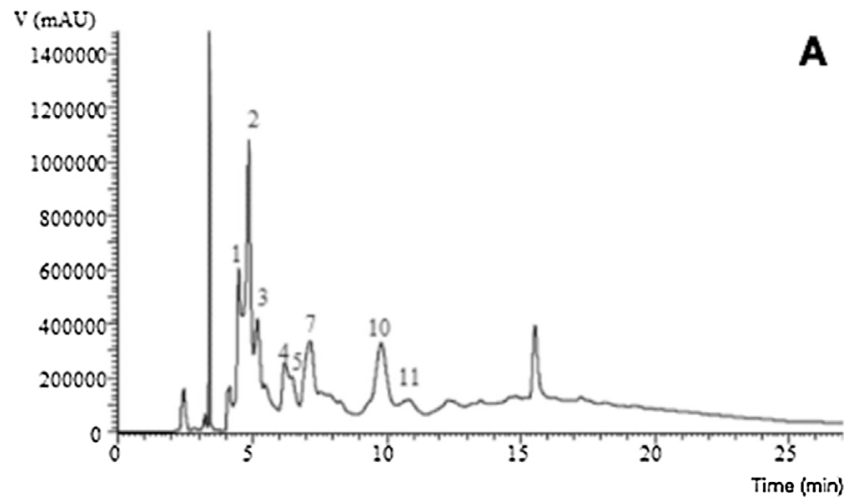

$\mathrm{V}(\mathrm{mAU})$
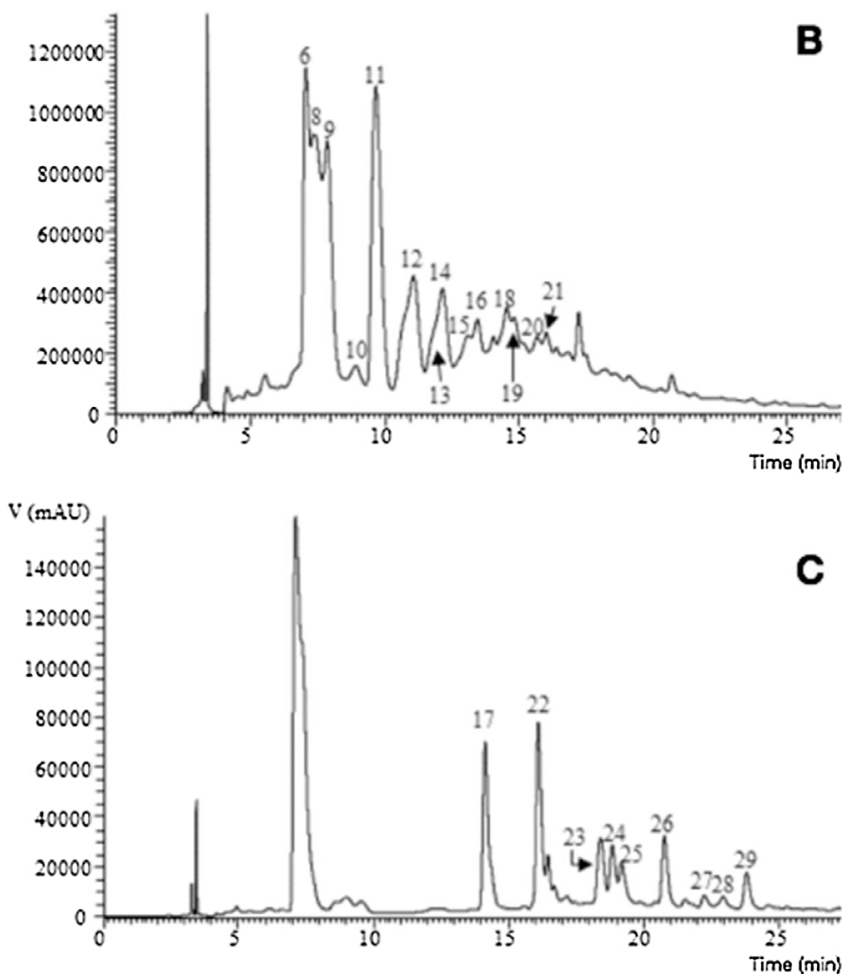

Fig. 1. Phenolic profile of $P$. americana (A) kernel recorded at $280 \mathrm{~nm}$, (B) and (C) peels recorded at $280 \mathrm{~nm}$ and $370 \mathrm{~nm}$, respectively.

the major compound found in kernel sample, while epicatechin (peak 10) was the major compound in peel samples. Peaks 3, 9 and 21 presented a pseudomolecular ion at $m / z 577$ and $\mathrm{MS}^{2}$ fragments at $m / z 451$ $(-126 \mathrm{mu}), 425(-152 \mathrm{mu})$ and $407(-152-18 \mathrm{mu})$ and also $\mathrm{m} / \mathrm{z}$ 289 and 287, coherent with the loss of two (epi)catechin units, being for that manner tentatively identified as B-type (epi)catechin dimers. Similarly, peaks 11 and $12\left([\mathrm{M}-\mathrm{H}]^{-}\right.$at $m / z$ 865), peaks 13 and 14 ([M$\mathrm{H}]^{-}$at $m / z$ 1153), peaks 15 and $16\left([\mathrm{M}-\mathrm{H}]^{-}\right.$at $\left.m / z 1441\right)$ and peaks 18, 19 and $20\left((\mathrm{M}-\mathrm{H})^{-}\right.$at $m / z$ 1729) were assigned as B-type (epi) catechin trimers, tetramers, pentamers and hexamers (Barros et al., 2015; Peláez-Cid et al., 2013; Rached et al., 2016).

The second major family of compounds found in avocado peels samples was flavonoids, mainly quercetin derivatives. Peak 24 was identified as quercetin-3-O-glucoside by comparison of its UV spectrum $\left(\lambda_{\max } 352 \mathrm{~nm}\right)$ and retention time with a commercial standard. Peaks $17,22,23,25,26$ and 28 presented a pseudomolecular ion $[\mathrm{M}-\mathrm{H}]^{-}$at $m / z 625,595,477,463,609$ and 579, respectively, and an unique $\mathrm{MS}^{2}$ fragment at $m / z 301$, being tentatively identified as quercetin-dihexoside, quercetin-pentoside-hexoside, quercetin-glucuronide, quercetinhexoside, quercetin-rhamnoside-hexoside and quercetin-rhamnosidepentoside, respectively. Peaks $27\left([\mathrm{M}-\mathrm{H}]^{-}\right.$at $\left.m / z 461\right)$ and $28\left([\mathrm{M}-\mathrm{H}]^{-}\right.$ 
at $m / z 491$ ) presented a unique $\mathrm{MS}^{2}$ fragments at $m / z 285$ and 315 , respectively, corresponding to the loss of a glucuronide unit $(-176 \mathrm{mu})$, being tentatively identified as kaempferol- and isorhamnetin-glucuronide, respectively.

Regarding the phenolic acids, caffeoylquinic acids and p-coumaroyl quinic acid isomers were the only compounds found in both samples, being the majority of them found in kernel samples, being peaks 8 and 6 the only phenolic acids found in peels samples. Peaks 1, 2, 6 and 8 were identified as caffeoylquinic acid derivatives according to their UV spectra and pseudomolecular ions, being previously found by Kosińska et al. (2012) and Ramos-Jerz et al. (2013) in peels and seeds of $P$. americana. Peak assignments of the different caffeoylquinic acids and $p$ coumaroyl quinic acid isomers were made using the recommended IUPAC numbering system (IUPAC, 1976) as also the hierarchical keys previously developed by Clifford et al. (2005, 2003). By comparison its UV spectrum $\left(\lambda_{\max } 326 \mathrm{~nm}\right)$ and retention time with a commercial standard, peak 8 was identified as 5-O-caffeoylquinic acid. Peaks 1 and $2\left([\mathrm{M}-\mathrm{H}]^{-}\right.$at $\left.m / z 353\right)$ were identified as cis 3-O-caffeoylquinic acid and trans 3-O-caffeoylquinic acid, respectively, according to their elution order and also yielding a base peak at $m / z 191$ and the ion at $m / z$ 179 with an intensity $>70 \%$ base peak, characteristic of 3-acylchlorogenic acids (Clifford et al., 2005, 2003). After UV irradiation (366 nm, $24 \mathrm{~h}$ ) of hydroxycinnamic acids in our laboratory, it was possible to observe that the hydroxycinnamoyl cis derivatives elute before the corresponding trans ones and therefore the assignment of cis and trans forms for peaks 1 and 2. Compound 6 was tentatively identified as 4-O-caffeoylquinic acid $\left([\mathrm{M}-\mathrm{H}]^{-}\right.$at $\left.m / z 353\right)$ according to the fragmentation pattern yielding a base peak at $m / z 173$ [quinic acid-H$\left.\mathrm{H}_{2} \mathrm{O}\right]^{-}$, accompanied by a secondary fragment ion at $\mathrm{m} / z 179(\sim 75 \%$ abundance), thus being distinct from the other two isomers (Clifford et al., 2005, 2003).

Taking into account the same findings, peaks 4 and 5 were tentatively identified as cis and trans 3-p-coumarouylquinic acids. (Kosińska et al., 2012) have previously identified these compounds in avocado peels.

\subsection{Antioxidant capacity of $P$. americana by-products}

Polyphenolic content in plants and fruits have been extensively studied due to the good impact these substances has shown as a potential health benefits arising from their biological activity as hepatoprotective, antiinflammatory, antiviral, antimicrobial and antioxidant activities (Ambigaipalan, 2015; Carocho and Ferreira, 2013; Dias et al., 2016; Kaur Kala et al., 2016). From the 29 different compounds found on $P$. americana by-products, 23 of them were found in peels $(227.9 \mathrm{mg} / \mathrm{g}$ of extract) and only 8 in kernels $(72.5 \mathrm{mg} / \mathrm{g}$ of extract), this represent around 3-fold higher polyphenols content in peels, these results obtained proved to be consistent with the other reports (Kosińska et al., 2012; Rodríguez-Carpena et al.,2011). It is also important here to stress, the higher phenolic content in $P$. americana byproducts compared with the edible pulp (Wang et al., 2010). This greater polyphenolic content has also displayed higher antioxidant capacity, and as expected $P$. americana peels proof to excel the kernels activity in around 1.5-fold higher in all the antioxidant tests performed and shown in Table 2, this result proved to be in concordance with Calderón-Oliver et al. (2016), Kosińska et al. (2012) and Saavedra et al. (2017). Although the differences in the total phenolic content between peels and kernels is 3 times higher, the antioxidant activity observed it is only around half (1.5) greater. This could be explained due to the different degrees of polymerization of the polyphenolic compounds of $P$. american peels. As it was mention before, Epicatechin was the most abundant compound in both by-products, peels are also majoritarian in different sort of B-type epicatechin dimer, trimer, tetramers and flavonol glycosides. On one hand Hollman et al. (1999) reports higher antioxidant activity on aglycones compared with glycosides, while Mishra et al. (2013) point out the difference between dimers, trimers,
Table 2

Antioxidant activity of $P$. americana by-products (peels and kernels).

\begin{tabular}{llll}
\hline $\mathrm{EC}_{50}(\mu \mathrm{g} / \mathrm{mL})$ & Peel & Kernel & $\begin{array}{l}t \text {-Students test } p \text { - } \\
\text { value }\end{array}$ \\
\hline $\begin{array}{l}\text { DPPH scavenging activity } \\
\text { Reducing power }\end{array}$ & $149 \pm 5$ & $220 \pm 3$ & $<0.001$ \\
$\begin{array}{l}\text { B-carotene bleaching } \\
\text { inhibition }\end{array}$ & $152 \pm 1$ & $27 \pm \pm 15$ & $<0.001$ \\
\begin{tabular}{l} 
TBARS \\
\hline
\end{tabular} & $11.7 \pm 0.1$ & $18.1 \pm 0.1$ & $<0.001$ \\
\hline
\end{tabular}

In each row different letters mean significant differences $(\mathrm{p}<0.05)$. $\mathrm{EC}_{50}$ values correspond to the sample concentration achieving $50 \%$ of antioxidant activity or 0.5 of absorbance in reducing power assay. $\mathrm{EC}_{50}$ values for the positive control trolox: $62.98 \mu \mathrm{g} /$ $\mathrm{mL}$ (DDPH), $45.71 \mu \mathrm{g} / \mathrm{mL}$ (reducing power), $10.25 \mu \mathrm{g} / \mathrm{mL}$ ( $\beta$-carotene bleaching inhibition) and $10.83 \mu \mathrm{g} / \mathrm{mL}$ (TBARS inhibition).

tetramers, heptamers and hexamers specificity on their properties as an antioxidants. These and other interaction could explain the differences obtained in the antioxidant activity between $P$. americana by-products, but in order to obtain better comprehension on this phenomena, more analysis have to be performed.

\subsection{Antimicrobial activity of $P$. americana by-products}

Flavonoids are known to be synthesized by plants in response to microbial infections, thus, it is not surprising this sort of compounds exhibit antimicrobial activity in many in vitro assays. Many flavonoid rich plant and fruits from different species have been reported with antimicrobial activity (Balouiri et al., 2016; Melgar et al., 2017; Rodrigo and Martínez-1, 2015; Sansano et al., 2017; Šiler et al., 2014; Vieira et al., 2016b). P. americana by-products have shown great antibacterial and moderate antifungal activity against the strains tasted Table 3. The bactericidal effect of the samples proved to outstand from the controls employed in 7 out of 8 different gram positive and negative

Table 3

Antibacterial and antifungal activity of P. americana by-products (peels and kernels).

\begin{tabular}{|c|c|c|c|c|c|c|c|c|c|}
\hline \multirow{2}{*}{$\begin{array}{l}\text { Antibacterial activity } \\
(\mathrm{mg} / \mathrm{mL})\end{array}$} & \multicolumn{3}{|l|}{ Peel } & \multicolumn{2}{|l|}{ Kernel } & \multicolumn{2}{|l|}{$\mathrm{C} 1$} & \multicolumn{2}{|l|}{$\mathrm{C} 2$} \\
\hline & MIC & \multicolumn{2}{|c|}{ MBC } & MIC & MBC & MIC & MBC & MIC & MBC \\
\hline \multicolumn{10}{|l|}{ Gram positive bacteria } \\
\hline Bacillus cereus & 0.015 & \multicolumn{2}{|c|}{0.030} & 0.020 & 0.030 & 0.10 & 0.20 & 0.25 & 0.40 \\
\hline Listeria monocytogenes & \multicolumn{2}{|c|}{0.030} & 0.075 & 0.030 & 0.070 & 0.20 & 0.30 & 0.40 & 0.50 \\
\hline Micrococcus flavus & 0.030 & \multicolumn{2}{|c|}{0.075} & 0.050 & 0.070 & 0.20 & 0.30 & 0.25 & 0.40 \\
\hline Staphylococcus aureus & 0.030 & \multicolumn{2}{|c|}{0.075} & 0.030 & 0.070 & 0.04 & 0.10 & 0.25 & 0.45 \\
\hline \multicolumn{10}{|l|}{ Gram negative } \\
\hline Enterobacter cloacae & \multicolumn{2}{|c|}{0.015} & 0.030 & 0.050 & 0.070 & 0.20 & 0.30 & 0.25 & 0.50 \\
\hline Escherichia coli & \multicolumn{2}{|l|}{0.30} & 0.45 & 0.15 & 0.30 & 0.20 & 0.30 & 0.40 & 0.50 \\
\hline $\begin{array}{l}\text { Pseudomonas } \\
\text { aeruginosa }\end{array}$ & 0.030 & \multicolumn{2}{|c|}{0.075} & 0.030 & 0.070 & 0.20 & 0.30 & 0.75 & 1.20 \\
\hline $\begin{array}{l}\text { Salmonella } \\
\text { typhimurium }\end{array}$ & 0.10 & \multicolumn{2}{|c|}{0.15} & \multicolumn{2}{|l|}{0.030} & 0.25 & 0.50 & 0.40 & 0.75 \\
\hline Antifungal activity (mg/ & & Peel & & Kerne & & C3 & & $\mathrm{C} 4$ & \\
\hline & & MIC & MFC & MIC & MFC & MIC & MFC & MIC & MFC \\
\hline Aspergillus fumigatus & & 0.3 & - & 0.3 & - & 0.25 & 0.50 & 0.15 & 0.20 \\
\hline Aspergillus versicolor & & 0.3 & - & 0.3 & - & 0.20 & 0.50 & 0.10 & 0.20 \\
\hline Aspergillus ochraceus & & 0.3 & - & 0.2 & 0.3 & 1.50 & 2.00 & 0.15 & 0.20 \\
\hline Aspergillus niger & & 0.3 & - & 0.3 & - & 0.20 & 0.50 & 0.15 & 0.20 \\
\hline Trichoderma viride & & 0.3 & - & 0.02 & 0.03 & 1.00 & 1.00 & 0.15 & 0.20 \\
\hline Penicillium funiculosum & & 0.3 & - & - & - & 0.20 & 0.50 & 0.20 & 0.25 \\
\hline Penicillium ochrochloron & & 0.3 & - & 0.3 & - & 2.50 & 3.50 & 0.20 & 0.25 \\
\hline $\begin{array}{l}\text { Penicillium verrucosum var } \\
\text { cyclopium }\end{array}$ & & 0.3 & - & 0.3 & - & 0.20 & 0.30 & 0.10 & 0.20 \\
\hline
\end{tabular}

C1, Streptomycin; C2, Ampicillin; C3, Ketoconazole; C4, Bifonazole; MIC, minimum inhibitory concentration; MBC, minimum bactericidal concentrations; $\mathrm{MBC}$, minimum fungicidal concentrations. 
strains, although, in this particular assay extracts from kernels displayed better MCB in 6 out of 8 strains, same power in B. cereus strain, and only worst power in E. cloacae strain. The results here exposed shown better performance when compared with the results reported by (Calderón-Oliver et al., 2016; Chia et al., 2010). Contrary to bactericidal effect, fungicidal effect only was shown in 2 strains but only with kernel extracts, from which, the better fungicidal effect was against Trichoderma viride. Comparing the fungistatic effect, both by-product extract were effective against all 8 strains, but only kernel extract did not shown affectivity against $P$. funiculosum. Both peels and kernels extract performed better at fungistastic level in 3 strains (A. ochraceus, $T$. viride and $P$. ochrochloron) when compared with ketoconazole antifungal commercial drug and kernel extract display better fungistastic effect in strain vs bifonazole (stronger control used). Antibacterial flavonoids might be having multiple cellular targets, rather than one specific site of action. Tsuchiya and Iinuma, (2000) suggested an alteration of membrane fluidity in hydrophilic and hydrophobic regions in this way flavonoids might reduce the fluidity of outer and inner layers of membranes. Mishra et al. (2009) propose that one of the molecular actions of flavonoids is to form complex with proteins through nonspecific forces such as hydrogen bonding and hydrophobic effects, as well as by covalent bond formation, this interactions have the ability to inactivate microbial adhesions, enzymes, cell envelope transport proteins, and so forth. In this sense, our understanding on the antimicrobial effect of polyphenols agrees with the previous mechanism of action mentioned.

\section{Conclusion}

One of the main goals of this research was to revalorize $P$. americana by-products by characterizing their main bioactive properties. With the assays performed we were able to detect new phenolic compounds in avocado by-products, quantify them and test their hydrophilic and lipophilic antioxidant capacity which shown to be superior to the capacity reported by other authors in the edible pulp. In the same manner, previous reports about antimicrobial activity were revised and confronted with the data obtained, the results obtained exhibit greater capacity against certain bacterial and fungal strains and wider study of strains tested. All the data recollected is just the begging of a series of experiments that have to be design in order to implement these functional molecules in different products and industries. The deeper analysis of bioactive compounds performed on $P$. americana by-products, will allow to continue searching the optimum process of extraction, purification and implementation as food ingredients.

\section{Acknowledgements}

The authors are grateful to the Foundation for Science and Technology(FCT, Portugal) and FEDER under Program PT2020 for financial support to CIMO (UID/AGR/00690/2013) and L. Barros contract. The authors would like to thank the Interreg España-Portugal for financial support through the project 0377_Iberphenol_6_E. B. Melgar thanks CONACyT for his grant (No. 329930). The authors are also grateful to the Serbian Ministry of Education, Science and Technological Development, grant number 173032 for financial support.

\section{References}

Šiler, B., Živković, S., Banjanac, T., Cvetković, J., Nestorović Živković, J., Ćirić, A Soković, M., Mišić, D., 2014. Centauries as underestimated food additives: Antioxidant and antimicrobial potential. Food Chem. 147, 367-376. http://dx.doi. org/10.1016/j.foodchem.2013.10.007.

Ambigaipalan, P., 2015. Phenolics and polyphenolics in foods, beverages and spices: antioxidant activity and health effects - A review. J. Funct. Foods 18, 820-897. http://dx.doi.org/10.1016/j.jff.2015.06.018.

Ayala-Zavala, J.F., Vega-Vega, V., Rosas-Domínguez, C., Palafox-Carlos, H., Villa-
Rodriguez, J.A., Siddiqui, M.W., Dávila-Aviña, J.E., González-Aguilar, G.A., 2011. Agro-industrial potential of exotic fruit byproducts as a source of food additives. Food Res. Int. 44, 1866-1874. http://dx.doi.org/10.1016/j.foodres.2011.02.021.

Azeredo, H.M.C., 2009. Betalains: properties, sources, applications, and stability - A review. Int. J. Food Sci. Technol. 44, 2365-2376. http://dx.doi.org/10.1111/j.13652621.2007.01668.x.

Balouiri, M., Sadiki, M., Ibnsouda, S.K., 2016. Methods for in vitro evaluating antimicrobial activity: a review. J. Pharm. Anal. 6, 71-79. http://dx.doi.org/10.1016/j. jpha.2015.11.005.

Barros, L., Calhelha, R.C., Queiroz, M.J.R.P., Santos-Buelga, C., Santos, E.A., Regis, W.C.B., Ferreira, I.C.F.R., 2015. The powerful in vitro bioactivity of Euterpe oleracea Mart. seeds and related phenolic compounds. Ind. Crops Prod. 76, 318-322. http:// dx.doi.org/10.1016/j.indcrop.2015.05.086.

Bessada, S.M.F., Barreira, J.C.M., Barros, L, Ferreira, I.C.F.R., Oliveira, M.B.P.P., 2016. Phenolic profile and antioxidant activity of Coleostephus myconis (L.) Rchb.f.: An underexploited and highly disseminated species. Ind. Crops Prod. 89, 45-51. http:// dx.doi.org/10.1016/j.indcrop.2016.04.065.

Calderón-Oliver, M., Escalona-Buendía, H.B., Medina-Campos, O.N., Pedraza-Chaverri, J., Pedroza-Islas, R., Ponce-Alquicira, E., 2016. Optimization of the antioxidant and antimicrobial response of the combined effect of nisin and avocado byproducts. LWT - Food Sci. Technol. 65, 46-52. http://dx.doi.org/10.1016/j.lwt.2015.07.048.

Carocho, M., Ferreira, I.C.F.R., 2013. A review on antioxidants, prooxidants and related controversy: natural and synthetic compounds, screening and analysis methodologies and future perspectives. Food Chem. Toxicol. 51, 15-25. http://dx.doi.org/10.1016/ j.fct.2012.09.021.

Chia, Raymond, Dykes, T.W., a, G., 2010. Antimicrobial activity of crude epicarp and seed extracts from mature avocado fruit (Persea americana) of three cultivars. Pharm. Biol. 48, 753-756. http://dx.doi.org/10.3109/13880200903273922.

Clifford, M.N., Johnston, K.L., Knight, S., Kuhnert, N., 2003. Hierarchical scheme for LCMS $n$ Identification of chlorogenic acids. J. Agric. Food Chem. 51, 2900-2911. http:// dx.doi.org/10.1021/jf026187q.

Clifford, M.N., Knight, S., Kuhnert, N., 2005. Discriminating between the six isomers of dicaffeoylquinic acid by LC-MSn. J. Agric. Food Chem. 53, 3821-3832. http://dx.doi. org/10.1021/jf050046h.

Destro dos Santos, C., Külzer Scherer, R., Schilling Cassini, A., Ferreira Marczak, L.D., Tessaro, I.C., 2016. Clarification of red beet stalks extract by microfiltration combined with ultrafiltration. J. Food Eng. 185, 35-41. http://dx.doi.org/10.1016/j. jfoodeng.2016.03.031.

Dias, M.I., Sousa, M.J., Alves, R.C., Ferreira, I.C.F.R., 2016. Exploring plant tissue culture to improve the production of phenolic compounds: a review. Ind. Crops Prod. 82, 9-22. http://dx.doi.org/10.1016/j.indcrop.2015.12.016.

FAO, IFAD, WFP, 2015. The state of food insecurity in the world. In: Meeting the 2015 International Hunger Targets: Taking Stock of Uneven Progress. Rome.

FAO, 2004. Avocado: post-harvest operation. Rome.

FDA, 2017. Q3C - Tables and List Guidance for Industry Q3C - Tables and List Guidance for Industry Q3C - Tables and List Guidance for Industry [WWW Document]. URL http://www.fda.gov/Drugs/ GuidanceComplianceRegulatoryInformation/Guidances/default.htm (Accessed 10 2.17).

Galanakis, C.M., 2012. Recovery of high added-value components from food wastes: conventional, emerging technologies and commercialized applications. Trends Food Sci. Technol. 26, 68-87. http://dx.doi.org/10.1016/j.tifs.2012.03.003.

Ghasemzadeh, A., Ghasemzadeh, N., 2011. Flavonoids and phenolic acids: role and biochemical activity in plants and human. J. Med. Plants Res. 5, 6697-6703. http://dx. doi.org/10.5897/JMPR11.363.

Gomes-Correa, R.C., de Souza, A.H.P., Calhelha, R.C., Barros, L., Glamoclija, J., Sokovic, M., Peralta, R.M., Bracht, A., Ferreira, I.C.F.R., 2015. Bioactive formulations prepared from fruiting bodies and submerged culture mycelia of the Brazilian edible mushroom Pleurotus ostreatoroseus Singer. Food Funct. 6, 2155-2164. http://dx.doi.org/ $10.1039 / \mathrm{C} 5 \mathrm{FO} 00465 \mathrm{~A}$.

Gong, M., Bassi, A., 2016. Carotenoids from microalgae: a review of recent developments. Biotechnol. Adv. 34, 1396-1412. http://dx.doi.org/10.1016/j.biotechadv.2016.10. 005.

Hollman, P.C., Bijsman, M.N., van Gameren, Y., Cnossen, E.P., de Vries, J.H., Katan, M.B., 1999. The sugar moiety is a major determinant of the absorption of dietary flavonoid glycosides in man. Free Radic. Res. 31, 569-573. http://dx.doi.org/10.1080/ 10715769900301141.

Hurtado-Fernández, E., Pacchiarotta, T., Longueira-Suárez, E., Mayboroda, O.A., Fernández-Gutiérrez, A., Carrasco-Pancorbo, A., 2013. Evaluation of gas chromatography-atmospheric pressure chemical ionization-mass spectrometry as an alternative to gas chromatography-electron ionization-mass spectrometry: avocado fruit as example. J. Chromatogr. A 1313, 228-244. http://dx.doi.org/10.1016/j.chroma. 2013.08.084.

Hurtado-Fernández, E., Pacchiarotta, T., Mayboroda, O.A., Fernández-Gutiérrez, A., Carrasco-Pancorbo, A., 2014. Quantitative characterization of important metabolites of avocado fruit by gas chromatography coupled to different detectors (APCI-TOF MS and FID). Food Res. Int. 62, 801-811. http://dx.doi.org/10.1016/j.foodres.2014.04. 038 .

IUPAC, IUPAC-IUB, 1976. Nomenclature of cyclitols. Biochem. J. 153, 23-31. http://dx. doi.org/10.1351/pac197437010283.

Kaderides, K., Goula, A.M., 2017. Development and characterization of a new encapsulating agent from orange juice by-products. Food Res. Int. 0-1. http://dx.doi. org/10.1016/j.foodres.2017.07.057.

Kaur Kala, H., Mehta, R., Tandey, R., Sen, K.K., Mandal, V., 2016. Ten years of research on phenolics (2005-2015): A status report. Pacific Sci. Rev. A Nat. Sci Eng. http://dx. doi.org/10.1016/j.psra.2016.07.002. 
Kosińska, A., Karamać, M., Estrella, I., Hernández, T., Bartolomé, B., Dykes, G.A., 2012. Phenolic compound profiles and antioxidant capacity of persea americana mill. peels and seeds of two varieties. J. Agric. Food Chem. 60, 4613-4619. http://dx.doi.org/ 10.1021/jf300090p.

López-Cobo, A., Gómez-Caravaca, A.M., Pasini, F., Caboni, M.F., Segura-Carretero, A., Fernández-Gutiérrez, A., 2016. HPLC-DAD-ESI-QTOF-MS and HPLC-FLD-MS as valuable tools for the determination of phenolic and other polar compounds in the edible part and by-products of avocado. LWT - Food Sci. Technol. 73, 505-513. http://dx.doi.org/10.1016/j.lwt.2016.06.049.

Li, J., Chen, Z., Di, D., 2012. Preparative separation and purification of Rebaudioside A from Stevia rebaudiana Bertoni crude extracts by mixed bed of macroporous adsorption resins. Food Chem. 132, 268-276. http://dx.doi.org/10.1016/j.foodchem. 2011.10.077.

Librán, C.M., Mayor, L., Garcia-Castello, E.M., Vidal-Brotons, D., 2013. Polyphenol extraction from grape wastes: solvent and $\mathrm{pH}$ effect. Agric. Sci. 4, 56-62. http://dx.doi. org/10.4236/as.2013.49B010.

Manach, C., Scalbert, A., Morand, C., Rémésy, C., Jiménez, L., 2004. Bioavailability, polyphenols: food sources and. Am. J. Clin. Nutr. 79, 727-747. http://dx.doi.org/10. 1038/nature05488.

Medina-Meza, I.G., Barbosa-Cánovas, G.V., 2015. Assisted extraction of bioactive compounds from plum and grape peels by ultrasonics and pulsed electric fields. J. Food Eng. 166, 268-275. http://dx.doi.org/10.1016/j.jfoodeng.2015.06.012.

Melgar, B., Dias, M.I., Ciric, A., Sokovic, M., Garcia-Castello, E.M., Rodriguez-Lopez, A.D., Barros, L., Ferreira, I., 2017. By-product recovery of Opuntia spp. peels: betalainic and phenolic profiles and bioactive properties. Ind. Crops Prod. http://dx.doi.org/10. 1016/j.indcrop.2017.06.011.

Mishra, A.K., Mishra, A., Kehri, H.K., Sharma, B., Pandey, A.K., 2009. Inhibitory activity of Indian spice plant Cinnamomum zeylanicum extracts against Alternaria solani and Curvularia lunata, the pathogenic dematiaceous moulds. Ann. Clin. Microbiol. Antimicrob. 8, 9. http://dx.doi.org/10.1186/1476-0711-8-9.

Mishra, A., Sharma, A.K., Kumar, S., Saxena, A.K., Pandey, A.K., 2013. Bauhinia variegata leaf extracts exhibit considerable antibacterial, antioxidant, and anticancer activities. Biomed. Res. Int. 2013. http://dx.doi.org/10.1155/2013/915436.

Naik, S.N., Goud, V.V., Rout, P.K., Dalai, A.K., 2010. Production of first and second generation biofuels: a comprehensive review. Renew. Sustain. Energy Rev. 14 578-597. http://dx.doi.org/10.1016/j.rser.2009.10.003.

Peláez-Cid, A.A., Velázquez-Ugalde, I., Herrera-González, A.M., García-Serrano, J., 2013. Textile dyes removal from aqueous solution using Opuntia ficus-indica fruit waste as adsorbent and its characterization. J. Environ. Manage. 130, 90-97. http://dx.doi. org/10.1016/j.jenvman.2013.08.059.

Rached, W., Calhelha, R.C., Fernandes, Â., Carvalho, A.M., Bennaceur, M., Marouf, A., Barros, L., Santos-Buelga, C., Ferreira, I.C.F.R., 2016. Phytochemical characterization and bioactive properties of Osyris quadripartita Salzm. ex Decne. leaves from Algeria. RSC Adv. 6, 72768-72776. http://dx.doi.org/10.1039/C6RA11787B.
Ramos-Jerz, M.D.R., Villanueva, S., Jerz, G., Winterhalter, P., Deters, A.M., 2013. 2013 persea americana mill. seed: fractionation, characterization, and effects on human keratinocytes and fibroblasts. Evidence-based complement. Altern. Med. eCAM 39124, 7. http://dx.doi.org/10.1155/2013/391247.

Rodríguez-Carpena, J.G., Morcuende, D., Estévez, M., 2011. Avocado by-products as inhibitors of color deterioration and lipid and protein oxidation in raw porcine patties subjected to chilled storage. Meat Sci. 89, 166-173. http://dx.doi.org/10.1016/j. meatsci.2011.04.013.

Rodrigo, D., Martínez-1, A., 2015. Antimicrobial activity of cauli fl ower (Brassica oleracea var Botrytis) by-product against Listeria monocytogenes. Food Control 50, 435-440. http://dx.doi.org/10.1016/j.foodcont.2014.09.031.

Saavedra, J., Córdova, A., Navarro, R., Díaz-Calderón, P., Fuentealba, C., AstudilloCastro, C., Toledo, L., Enrione, J., Galvez, L., 2017. Industrial avocado waste: functional compounds preservation by convective drying process. J. Food Eng. 198, 81-90. http://dx.doi.org/10.1016/j.jfoodeng.2016.11.018.

Sansano, S., Rivas, A., Pina-Pérez, M.C., Martinez, A., Rodrigo, D., 2017. Stevia rebaudiana bertoni effect on the hemolytic potential of listeria monocytogenes. Int. J. Food Microbiol. http://dx.doi.org/10.1016/j.ijfoodmicro.2017.03.006.

Sharma, K., Mahato, N., Cho, M.H., Lee, Y.R., 2017. Converting citrus wastes into valueadded products: economic and environmently friendly approaches. Nutrition 34, 29-46. http://dx.doi.org/10.1016/j.nut.2016.09.006.

Tsuchiya, H., Iinuma, M., 2000. Reduction of membrane fluidity by antibacterial sophoraflavanone G isolated from Sophora exigua. Phytomedicine 7, 161-165. http:// dx.doi.org/10.1016/S0944-7113(00)80089-6.

UN DESA, 2015. World Population Prospects: The 2015 Revision New York.

Vieira, V., Barros, L., Martins, A., Ferreira, I., 2016a. Nutritional and biochemical profiling of leucopaxillus candidus (Bres.) singer wild mushroom. Molecules 21, 99. http://dx.doi.org/10.3390/molecules21010099.

Vieira, V., Fernandes, Â., Barros, L., Glamočlija, J., Ćirić, A., Stojković, D., Martins, A., Soković, M., Ferreira, I.C.F.R., 2016b. Wild Morchella conica Pers. from different origins: a comparative study of nutritional and bioactive properties. J. Sci. Food Agric. 96, 90-98. http://dx.doi.org/10.1002/jsfa.7063.

WHO, 2014. GLOBAL STATUS REPORT on noncommunicable diseases 2014. "Attaining the nine global noncommunicable diseases targets; a shared responsibility \& quot.

Wang, W., Bostic, T.R., Gu, L., 2010. Antioxidant capacities, procyanidins and pigments in avocados of different strains and cultivars. Food Chem. 122, 1193-1198. http://dx. doi.org/10.1016/j.foodchem.2010.03.114.

Yamashita, C., Chung, M.M.S., dos Santos, C., Mayer, C.R.M., Moraes, I.C.F., Branco, I.G., 2017. Microencapsulation of an anthocyanin-rich blackberry (Rubus spp.) by-product extract by freeze-drying. LWT - Food Sci. Technol. 84, 256-262. http://dx.doi.org/ 10.1016/j.lwt.2017.05.063.

da Silva, R.P.F.F., Rocha-Santos, T.A.P., Duarte, A.C., 2016. Supercritical fluid extraction of bioactive compounds. TrAC - Trends Anal. Chem. 76, 40-51. http://dx.doi.org/ 10.1016/j.trac.2015.11.013 